\title{
The Methylene Chloride Fraction of Trichosanthis Fructus Induces Apoptosis in U937 Cells through the Mitochondrial Pathway
}

\author{
Eun-Ok LeE, ${ }^{a}$ Ju-Ryoung LeE, ${ }^{a}$ Kwan-Hyun KIm, ${ }^{a}$ Nam-In BAeK, ${ }^{b}$ Soo-Jin LeE, ${ }^{c}$ Bog-Hieu LeE, ${ }^{d}$ \\ Kyung-Dong Cно, ${ }^{d}$ Kyoo-Seok AнN, ${ }^{e}$ and Sung-Hoon Kiм ${ }^{*, a}$ \\ ${ }^{a}$ Department of Oncology, Graduate School of East-West Medical Science; ${ }^{b}$ Graduate School of Biotechnology \& Plant \\ Metabolism Research Center, Kyunghee University; Yongin 449-701, Republic of Korea: ${ }^{c}$ College of Oriental Medicine, \\ Sangji University; 660 Woosan-dong, Wonju 220-702, Republic of Korea: ' Oriental Medical College, Kyunghee \\ University; Seoul 131-701, Republic of Korea: and ${ }^{e}$ Department of Food and Nutrition, Chung-Ang University; Ansung \\ 456-756, Republic of Korea. Received May 25, 2005; accepted August 17, 2005
}

\begin{abstract}
Trichosanthis kirilowii MAXIM has been used as a folk remedy to treat diabetes, leukemia, and breast cancer. In the present study, the apoptotic mechanism of the methylene chloride fraction of Trichosanthis Fructus (MCTF) was investigated in human leukemic U937 cells. MCTF exhibited antiproliferative effectsagainst U937 cells $\left(\mathrm{IC}_{50}=c a .8 \mu \mathrm{g} / \mathrm{ml}\right)$. Apoptotic bodies were observed in MCTF-treated U937 cells in the TUNEL assay. We also confirmed that MCTF significantly increases annexin $\mathrm{V}^{+}$/propidium iodide-cells using FACS analysis. MCTF treatment activated caspase-8, -9 and -3, and led to cleaved poly (ADP-ribose) polymerase and release of cytochrome $c$ into cytosol in a concentration-dependent manner, while MCTF did not affect Bax or Bcl-2 protein levels as shown by Western blot analysis. Taken together, these results indicate that MCTF can induce apoptosis in $\mathbf{U} 937$ cells chiefly via a mitochondrial-mediated pathway and suggest that Trichosanthis Fructus can be used in cancer treatment as a chemopreventive agent.
\end{abstract}

Key words Trichosanthis kirilowii; apoptosis; caspase; mitochondrial pathway; U937 cell

In spite of advances in the development of chemotherapeutic drugs, radiotherapy, and surgery, most advanced cancers remain incurable in modern times. These treatment options all have significant side effects or constitute financial burdens on patients. Chemoprevention of cancer with synthetic compounds or naturally occurring agents is a rational and economical approach to fight cancer from the root. Recently, Oriental medicinal herbs with anticancer activity are on the spotlight as a complementary/alternative medicine. ${ }^{1-3)}$

Trichosanthes kirilowii МАхІм is a perennial herb distributed in the mountains of the central and southern districts of Korea. Its roots have traditionally been used for the treatment of diabetes, cancer, and bronchial diseases. ${ }^{4,5)}$ The roots were reported to inhibit allergy, diabetes, cancer, and inflammation pharmacologically. ${ }^{6-9)}$ On the contrary, the biological activity of Trichosanthis Fructus, seeds remains unclear except for antiinflammatory activity ${ }^{10}$ ) though Trichosanthis Fructus has been used in the treatment of breast cancer, leukemia, and Ehrlich's ascitic carcinoma as a folk remedy. ${ }^{5)}$ Therefore, in the present study, as a first step to provide the scientific evidence for traditional practice, the underlying apoptotic mechanism of the methylene chloride fraction of Trichosanthis Fructus was investigated in human leukemic U937 cells.

\section{MATERIALS AND METHODS}

Materials Trichosantahis Fructus, RPMI 1640 medium, fetal bovine serum, and antibiotic-antimycotic were purchased from Gibco (Grand Island, NY, U.S.A.). HEPES, sodium bicarbonate, 2,3-bis[2-methoxy-4-nitro-5-sulfophenyl]-2Htetrazolium-5-carboxanilide (XTT), propidium iodide (PI), RNase A, $N$-methyldibenzo-pyrazine methyl sulfate (PMS) and poly-L-lysine were from Sigma Chemical Co. (St. Louis, MO, U.S.A.). The Dead End fluorometric TdT-mediateddUTP Nick-End Labeling (TUNEL) assay Kit was from Promega (Madison, WI, U.S.A.) and Annexin V-FITC Apop- tosis Detection Kit I was from BD Biosciences (San Diego, CA, U.S.A.). The protease inhibitor cocktail was from Boehringer Mannheim (Indianapolis, IN, U.S.A.). The DC protein assay kit II was from Bio-Rad (Hercules, CA, U.S.A.). Mouse anti-human/mouse bax (sc-7480) was from Santa Cruz Biotechnology (Santa Cruz, CA, U.S.A.). Mouse anti-human/mouse cytochrome $c$ (556433) and mouse antihuman poly (ADP-ribose) polymerase (PARP) (556494) were from PharMingen (San Diego, CA, U.S.A.). Rabbit anti-human/mouse caspase- 8 , rabbit anti-human/mouse cleaved caspase-3 (9661), and rabbit anti-human cleaved caspase-9 (9505) were from Cell Signaling Technology (Beverly, MA, U.S.A.). Mouse anti-human/mouse $\beta$-actin (A5316) was from Sigma Chemical Co. Goat anti-mouse IgG horseradish peroxidase (HRP)-conjugated secondary antibody was from Zymed (San Francisco, CA, U.S.A.) and goat anti-rabbit IgG HRP-conjugated secondary antibody from Pierce (Rockford, IL, U.S.A.). 4X NuPAGE LDS sample buffer, 4-12\% NuPAGE Bis-Tris gels, and NuPAGE MES SDS running buffer were from Invitrogen (Carlsbad, CA, U.S.A.). Hybond ECL transfer membrane and ECL Western blotting detection kit were from Amersham Pharmacia (Arlington Heights, IL, U.S.A.). X Ray films were from Agfa-Gevaert (CP-BU, N.V., Belgium).

Plant Extraction Trichosanthis Fructus, the seed of Trichosanthes kirilowii МАхІм harvested in Jangsoo, Chonbuk province, was kindly authenticated by Professor Nam-In Baek, Department of Oriental Herbal Materials, KyungHee University, and stored in our at my laboratory under the code MCKT-2003-10-20. One kilogram of dried Trichosanthis Fructus was extracted three times with methanol $(\mathrm{MeOH})$. $\mathrm{MeOH}$ solvent was then removed by evaporation, and the dried $\mathrm{MeOH}$ extract was obtained. The $\mathrm{MeOH}$ extract was then dissolved in water and partitioned successively with equal volumes of hexane (Hx), methylene chloride (MC), ethyl acetate (EtOAc), and butanol $(\mathrm{BuOH})$ to obtain the cor- 
responding fractions and the residue of water-soluble fraction. The fractionated solvent fractions were concentrated with a rotary evaporator and then lysophilized with a freeze dryer. The yields of hexane (Hx), methylene chloride (MC), ethyl acetate (EA), and butanol fractions of solvent extracts of Trichosanthis Fructus and residue were $63.98 \%, 2.73 \%$, $0.93 \%, 5.01 \%$, and $25.93 \%$, respectively.

Thin Layer Chromatographic Analysis The MC fraction of Trichosanthis Fructus was compared with other solvent fractions using thin-layer chromatography (TLC) on precoated silica gel $60 \mathrm{~F}_{254}$ plates with chloroform-methanol $8: 1(\mathrm{v} / \mathrm{v})$ as the mobile phase. The spots were detected by spraying with $10 \%$ sulfuric acid on the TLC plates.

Cell Culture Human leukemic U937 cells (CRL1593.2) were obtained from the American Type Culture Collection. The cells were cultured in RPMI 1640 medium supplemented with $10 \%$ heat-inactivated fetal bovine serum, HEPES buffer $25 \mathrm{~mm}, 100$ units/ml of antibiotic-antimycotic, and sodium bicarbonate $2 \mathrm{~g} / 1$ at $37^{\circ} \mathrm{C}$ in a humidified atmosphere containing $5 \% \mathrm{CO}_{2}$.

Proliferation Assay Proliferation assay was measured using the tetrazolium salt 2,3-bis-(2-methoxy-4-nitro-5[(sulfenylamino) carbonyl]-2H-tetrazolium-hydroxide (XTT) colorimetric assay. The various solvent fractions of Trichosanthis Fructus were dissolved in dimethyl sulfoxide (DMSO). The cells were seeded onto 96-well microplates at a density of $2 \times 10^{4}$ cells per well in $100 \mu \mathrm{l}$ of serum-free RPMI 1640 medium containing solvent extracts of Trichosanthis Fructus at various concentrations of 10, 20, 40, and $60 \mu \mathrm{g} / \mathrm{ml}$. After incubation at $37^{\circ} \mathrm{C}$ in a humidified incubator for $24 \mathrm{~h}, 50 \mu \mathrm{l}$ of XTT $(1 \mathrm{mg} / \mathrm{ml}$ in PBS) was added to each well and incubated at $37^{\circ} \mathrm{C}$ for $2 \mathrm{~h}$ and the optical density was measured using a microplate reader (Molecular Devices Co.) at wavelength of $450-650 \mathrm{~nm}$. Cell survival was determined as a percentage of viable cells in the Trichosanthis Fructus-treated cells versus PBS-treated controls.

TUNEL Assay TUNEL-positive cells were detected using the Dead End Fluorometric TUNEL System (Promega) according to the manufacturer's instructions. Briefly, U937 cells were treated with MCTF and the cells were washed and harvested after $12 \mathrm{~h}$. The cells were fixed with $4 \%$ methanolfree formaldehyde solution for $25 \mathrm{~min}$ at $4{ }^{\circ} \mathrm{C}$ and added with $0.2 \%$ Triton X-100 solution for $5 \mathrm{~min}$ at $4{ }^{\circ} \mathrm{C}$. Intracellular DNA fragments were then labeled by exposing the cells to fluorescein-12-dUTP and terminal deoxynucleotidyltransferase for $1 \mathrm{~h}$ at $37^{\circ} \mathrm{C}$, in a humidified atmosphere and protected from light. The reaction was stopped by adding SSC solution, followed by washing the cells three times and staining with PI solution $1 \mu \mathrm{g} / \mathrm{ml}$ in PBS containing DNase-free RNase $250 \mu \mathrm{g} / \mathrm{ml}$ for $15 \mathrm{~min}$ at room temperature in the dark. After washing with PBS, slides were mounted in 30\% glycerol in PBS and analyzed under a Axiovert S 100 fluorescence microscope (Carl Zeiss, Inc., U.S.A.).

FACS Analysis To confirm apoptosis induction, annexin $\mathrm{V}$ and PI double staining was performed using the Annexin V-FITC Apoptosis Detection Kit I as described by the manufacturer. U937 cells $\left(6 \times 10^{6}\right)$ treated with MCTF for $24 \mathrm{~h}$ were harvested and washed with cold PBS. Binding buffer $100 \mu \mathrm{l}$ with annexin $\mathrm{V} 4 \mu \mathrm{l}$ was added to the cells and incubated for $15 \mathrm{~min}$ in the dark. Each sample was also incubated with PI $4 \mu \mathrm{l}$ for $15 \mathrm{~min}$ in the dark. The cells stained with an- nexin V-FITC were analyzed with FACS Vantage SE (Becton Dickinson, San Jose, CA, U.S.A.) using CellQuest Software, which was also used to determine the percentage of apoptotic cells. PI was excited at $488 \mathrm{~nm}$, and fluorescence was analyzed at $620 \mathrm{~nm}$.

Western Blot Analysis U937 cells $\left(2 \times 10^{6}\right)$ were treated with various concentrations of MCTF for $12 \mathrm{~h}$. After incubation, the cells were harvested, washed three times with PBS, and then the cell lysates were prepared with lysis buffer [50 mм HEPES-NaOH, pH 7.4, 150 mм NaCl, 0.1\% (w/v) Triton X-100, sodium fluoride $50 \mathrm{~mm}$, sodium orthovanadate $0.1 \mathrm{~mm}$, EDTA $1 \mathrm{~mm}$, phenylemethylsulfonyl fluoride (PMSF) $1 \mathrm{~mm}$, aprotinin $1 \mu \mathrm{g} / \mathrm{ml}$, and leupeptin $1 \mu \mathrm{g} / \mathrm{ml}$. After centrifugation, the quantity of protein was measured using the DC protein assay kit (Bio-Rad Laboratories) with bovine serum albumin (BSA) as the standard. The samples $(20 \mu \mathrm{g}$ of total protein) were mixed with $5 \times$ SDS sample buffer [Tris- $\mathrm{HCl} \quad 0.3 \mathrm{M}$ (pH 6.8), 25\% 2-mercaptoethanol, 12\% SDS, EDTA $25 \mathrm{~mm}, 20 \%$ glycerol, and $0.1 \%$ bromophenol blue] and the mixtures were boiled at $95^{\circ} \mathrm{C}$ for $5 \mathrm{~min}$. They were subjected to SDS-PAGE and transferred to nitrocellulose membranes (Amersham Biosciences). The membranes were blocked with blocking solution containing 5\% skim milk in PBS for $2 \mathrm{~h}$ at room temperature. The membranes were then probed with Bcl-2, Bax (Santa Cruz Biotechnology Inc.), procaspase-8, cleaved caspase-9, cleaved caspase3, PARP (Cell Signaling Technology, Beverly, MA, U.S.A.), and $\beta$-actin (Sigma Chemical) antibodies. The primary antibodies were detected using HRP-conjugated goat anti-mouse IgG (Pharmingen), and visualized with ECL Western Blotting Detection Reagents (Amercham Biosciences).

Isolation of Cytosol Fraction and Assessment of $\mathbf{C y}$ tochrome $c$ Release U937 cells $\left(6 \times 10^{6}\right)$ treated with MCTF for $24 \mathrm{~h}$ were harvested and washed with cold PBS. Cell pellets were lysed in $40 \mu \mathrm{l}$ of lysis buffer (HEPES 20 $\mathrm{mm} / \mathrm{NaOH}, \mathrm{pH} 7.5$, sucrose $250 \mathrm{~mm}, \mathrm{KCl} 10 \mathrm{~mm}, \mathrm{MgCl}_{2}$ $2 \mathrm{~mm}$, EDTA $1 \mathrm{~mm}$, DTT $1 \mathrm{~mm}$, protease inhibitor cocktail) for $20 \mathrm{~min}$ on ice. The pellets were homogenized by 10 passages using a 22 gauge needle. The homogenate was centrifuged at $25000 \mathrm{~g}$ for $30 \mathrm{~min}$ at $4{ }^{\circ} \mathrm{C}$ and protein contents in the supernatant were measured using a Bio-Rad DC Protein Assay Kit II. The lysates containing $20 \mu \mathrm{g}$ of protein were analyzed with Western blotting for cytochrome $c(1: 2000$ dilution) and $\beta$-actin $(1: 20000)$.

Statistical Analysis All values are expressed as mean \pm S.D. Statistical significance was compared between each treated celll group and control cells using by the Student's $t$ test. Values with $p<0.05$ were considered significantly different from untreated control values.

\section{RESULTS}

Antiproliferative Activity of Solvent Extracts of Trichosanthis Fructus on U937 Cells All the extracts of Trichosanthis Fructus were evaluated for their antiproliferative activities in human leukemic U937 cells. As shown in Fig. 1, within $24 \mathrm{~h}$ of exposure, the Hx fraction and the methanol extract had similar potency in decreasing cell viability with an $\mathrm{IC}_{50}$ value of $c a .13 \mu \mathrm{g} / \mathrm{ml}$. The EA fraction was less effective, with an $\mathrm{IC}_{50}$ value of $c a .25 \mu \mathrm{g} / \mathrm{ml}$, and the $\mathrm{BuOH}$ and residual fractions had no effect on antiproliferative activity at 


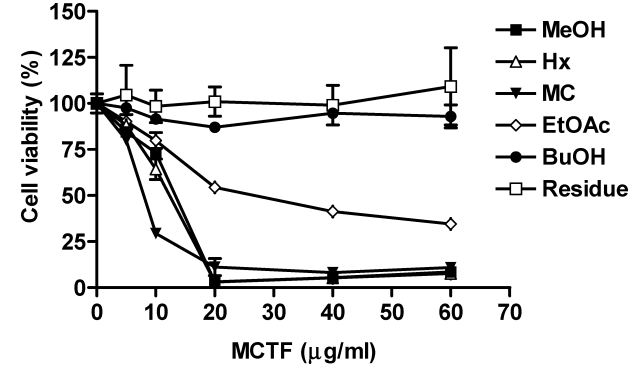

Fig. 1. Antiproliferative Activity of Various Solvent Extracts of Trichosanthis Fructus in U937 Cells

Cells were treated with various concentrations of each solvent extract for $24 \mathrm{~h}$ in serum-free medium, and cell viability was determined using XTT assay. All data are expressed as mean \pm S.D

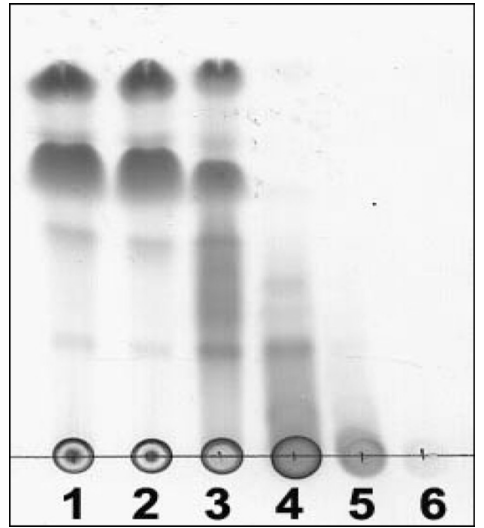

Fig. 2. Thin-layer Chromatographic Patterns of Trichosanthis Fructus in Chloroform : $\mathrm{MeOH}(8: 1)$

The spots were detected by spraying $10 \%$ sulfuric acid on the TLC plates. Lane 1 , methanol extract; lane 2, hexane fraction; lane 3, methylene chloride fraction; lane 4 , ethyl acetate fraction; lane 5, butanol fraction; lane 6 , residue fraction.

levels as high as $100 \mu \mathrm{g} / \mathrm{ml}$. On the contrary, the MC fraction showed the greatest inhibition of U937 cell proliferation, with an $\mathrm{IC}_{50}$ value of $c a .8 \mu \mathrm{g} / \mathrm{ml}$. Thus it can be assumed that the cytotoxic activity of the MC fraction may be due to synergistic effects of the two fast-moving spots in the Hx (lane 2) or methanol extracts (lane 1) with the enriched band below these two major spots shown in Fig. 2.

MCTF-Induced Apoptotic Morphologic Changes in U937 Cells The TUNEL assay was performed to detect apoptotic morphologic changes in cells treated with $30 \mu \mathrm{g} / \mathrm{ml}$ of MCTF for $24 \mathrm{~h}$ and stained with fluorescein-12-dUTP and PI. Apoptotic cells with DNA fragmentation showed green fluorescence and represented half of the cell population (Fig. $3)$.

To confirm further the induction of apoptosis, and not necrosis, FACS analysis with annexin V staining was performed. During apoptosis, the phosphatidylserines of the inner cell membrane flip to the outside and become accessible to annexin V. As shown in Fig. 4, MCTF increased the number of annexin V-positive cells to $40 \%$ at the dose of 30 $\mu \mathrm{g} / \mathrm{ml}$ in a concentration-dependent manner.

MCTF Induced Caspase Activation, and Cytochrome c Release from Mitochondria To determine whether caspase pathways are involved in the apoptosis induced by MCTF, the expression of cleaved (activated) forms of cas-
A

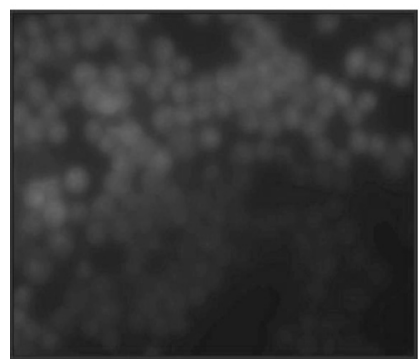

B

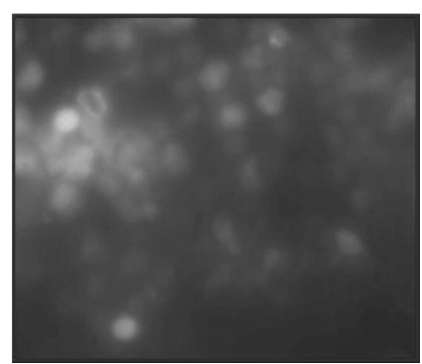

Fig. 3. MCTF-Induced Morphologic Changes of U937 Cells

Cells were treated with MCTF for $24 \mathrm{~h}$ and harvested. Fixed and permeabilized cells were stained with TdT enzyme buffer containing fluorescein-12-dUTP and PI and analyzed under a fluorescence microscope. (A) Control; (B) MCTF $30 \mu \mathrm{g} / \mathrm{ml}$. Nonapoptotic cells appear with intact genomic DNA (A), whereas apoptotic cells appear with fragmented DNA (B).

\section{A}

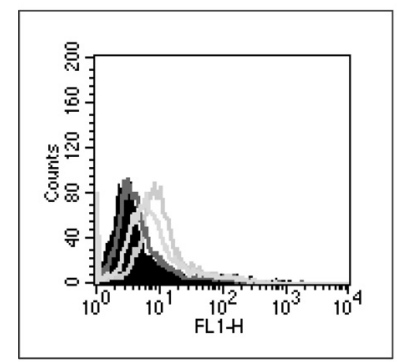

B

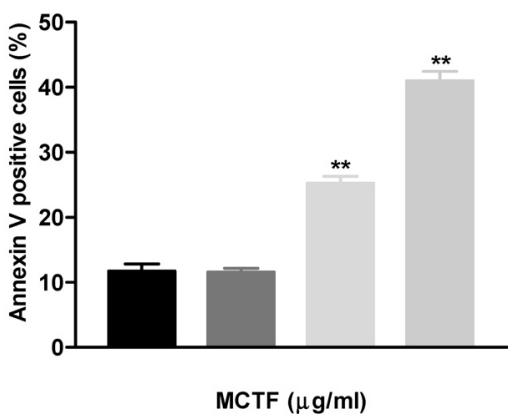

Fig. 4. MCTF-Induced Apoptosis in U937 Cells

(A) Cells were treated with MCTF for $24 \mathrm{~h}$ and harvested. The cells were stained with annexin $\mathrm{V}$ and PI for $15 \mathrm{~min}$ in the dark. The cells stained with annexin V-FITC were analyzed using CellQuest Software with FACSVantage SE flow cytometry. (B) The fraction of annexin V-positive cells is indicated. All data are expressed as mean \pm S.D. $* p<0.05, * * p<0.01$.

pase- 9 and caspase- 3 was detected using Western blot as shown in Fig. 5A. Whereas a significant increase in cleaved caspase- 9 was detectable at $30 \mu \mathrm{g} / \mathrm{ml}$, cleaved caspase- 3 was detectable at $20 \mu \mathrm{g} / \mathrm{ml}$ and higher doses. In addition, the expression of procaspase- 8 was decreased in MCTF-treated U937 cells at a concentration of $30 \mu \mathrm{g} / \mathrm{ml}$. Furthermore, the caspase-3 substrate PARP was cleaved at an exposure concentration of $20 \mu \mathrm{g} / \mathrm{ml}$ and higher.

Because a major mechanism of caspase-9 activation was through cytochrome $c$ released from mitochondria, we examined the effect of MCTF on cytosolic cytochrome $c$ levels 
after $24 \mathrm{~h}$ exposure (Fig. 5B). Cytosolic cytochrome $c$ was markedy increased, indicating release from mitochondria into the cytosol by MCTF. The exposure to MCTF did not change the expression of the proapoptotic protein Bax and antiapoptotic protein $\mathrm{Bcl}-2$, which are known to regulate mitochondrial integrity (Fig. 5B).

\section{DISCUSSION}

One of the attractive strategies considered in current cancer chemotherapy is dietary or pharmaceutical manipulation to induce the death of malignant cells through apoptosis. ${ }^{11)}$ Many reports show that herbal medicines and compounds isolated from natural products have potential antitumor activity by inducing apoptosis. ${ }^{1,2)}$ There is accumulating evidence that naturally occurring compounds and many chemotherapeutic agents with antitumor effects can trigger the apoptosis of cancer cells. ${ }^{3,12}$ Thus the study presented here focused on the apoptotic mechanism of Trichosanthis Fructus.

MCTF showed the great cytotoxicity against U937 leukemic cells, with an $\mathrm{IC}_{50}$ value of $8 \mu \mathrm{g} / \mathrm{ml}$, among the various solvent fractions examined. This increased potency may be due to the synergistic effects of many different entities in the two brown major spots with an enriched band of the MC fraction shown in TLC analysis.

DNA nuclesosomal fragmentation is a hallmark of apoptotic death. Using the TUNEL assay to detect broken DNA, we found more immunofluorescent apoptotic bodies in MCTF-treated U937 leukemic cells compared with intact control cells, suggesting the apoptotic activity of MCTF.

Externalization of the inner membrane phosphatidylserine to the external cellular environment is one of the earliest markers of apoptotic death. Annexin V-FITC binds to phosphatidylserine and can be used to detect early stages of apoptosis. ${ }^{13)}$ PI cannot enter whole cells with intact membranes and is used to differentiate between early apoptotic (annexin V-positive, PI-negative) and late apoptotic or necrotic cells (annexin V and PI double positive). ${ }^{14)}$ We therefore confirmed that the exposure of U937 cells to MCTF resulted in an increase in the apoptotic cell population in a concentration-dependent manner.

Apoptosis is a strictly controlled mechanism of cell suicide triggered by certain internal or external signals. ${ }^{15)}$ Caspases are a family of intracellular cysteine proteases that exist in a latent form in cells but become activated in response to apoptotic stimuli. ${ }^{16)}$ At present, two major pathways of caspase activation have been revealed. One is the death receptor-mediated apoptosis pathway where tumor necrosis factor family activates upstream caspase- $8,{ }^{17)}$ and the other is the mitochondrial-mediated apoptosis pathway where cytochrome $c$ is released from the mitochondria and activates procaspase-9. ${ }^{18)}$ In our study, MCTF decreased the expression of procaspase-8, and increased the level of cleaved (activated) caspases 9 and 3 at $30 \mu \mathrm{g} / \mathrm{ml}$, suggesting that MCTF exerts cytotoxicity through caspase-dependent pathways. Caspase involvement was further confirmed by the cleavage of the caspase- 3 substrate PARP. The activation of caspases 9 and 3 implies the involvement of the mitochondrial pathway in MCTF-induced apoptosis. Increased release cytochrome $c$ into cytosol in a concentration-dependent manner in MCTF-exposed cells supports this contention.
A

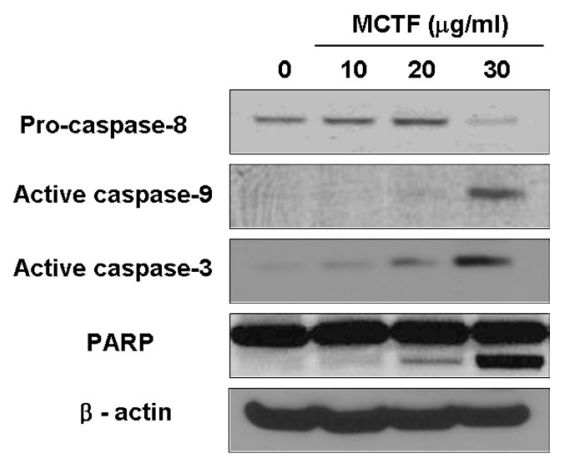

B

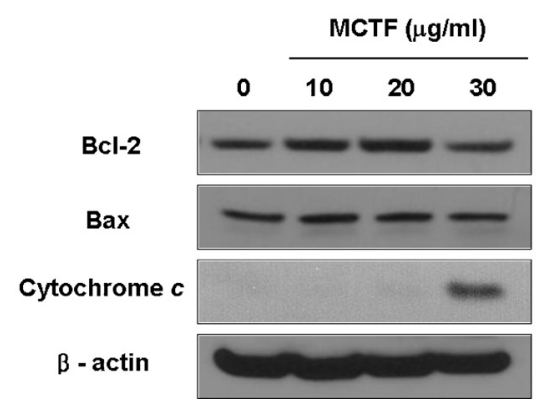

Fig. 5. MCTF-Induced Caspases Activation, PARP Degradation and Cytochrome $c$ Release from Mitochondria in U937 Cells

Cells were treated with MCTF for $24 \mathrm{~h}$. The cell lysates containing $20 \mu \mathrm{g}$ of proteins were separated on gels, transferred to Hybond ECL transfer membrane, and probed with caspases, PARP (A), and Bax and Bcl-2 (B). For cytosolic cytochrome $c$, mitochondria-free cytosol was prepared and analyzed using Western blotting (B). The proteins were developed using an ECL Western blotting detection kit and exposed to Xray films. Protein contents were normalized by probing the same membrane with $\beta$ actin antibody.

The activation of caspase 8 can directly activate caspase-3. Caspsae- 8 activation can crosstalk with the mitochondria mediated pathway by cleavage of Bid, a $\mathrm{BH} 3$ domain containing proapoptotic Bcl-2 family member, which usually exists in an inactive form in the cytoplasm and translocates to the mitochondria when cleaved to induce the release of cytochrome c. $^{19,20)}$ MCTF $30 \mu \mathrm{g}$ activated caspase 8 , while it did not affect the expression of Bax and Bcl-2 in U937 cells. These data suggest the possible involvement of an extrinsic pathway for the induction of apoptosis by MCTF. However, additional research is needed to delineate the relative contribution of this pathway to apoptosis execution.

In summary, MCTF exerted strong cytotoxicity against U937 cells. It significantly increased the sub- $\mathrm{G}_{1}$ cell population and showed apoptotic bodies in the TUNEL assay. MCTF activated caspases 8,9 , and 3, resulting in increased cleavage of PARP and cytochrome $c$ release from the mitochondria to the cytosol. Taken together, these results strongly indicate that MCTF may exert antitumor activity via induction of apoptosis through activation chiefly via the mitochondria mediated pathway. These data provide scientific evidence that Trichosanthis Fructus can be useful as a cancer chemopreventive agent.

Acknowledgments This study was supported by research grants from Agricultural R\&D Promotion Center and 
Ministry of Health and Welfare and Biogreen 21 Program.

\section{REFERENCES}

1) Lee E. O., Kwon B. M., Song G. Y., Chae C. H., Kim H. M., Shim I. S., Ahn K. S., Kim S. H., Life Sci., 74, 2313-2326 (2004).

2) Huh J. E., Lee E. O., Kim M. S., Kang K. S., Kim C. H., Cha B. C., Surh Y. J., Kim S. H., Carcinogenesis, 26, 1436-1445 (2005).

3) Huh J. E., Kang K. S., Chae C., Kim H. M., Ahn K. S., Kim S. H., Biochem. Pharmacol., 67, 1811-1818 (2004).

4) Koh K., Jeon E., "Fern, Fern Allies and Seed Bearing Plants of Korea," Iljin Press, Seoul, 2003, p. 645.

5) Qu M., Xu H., Li Y., Luo H., "An Illustrated Guide of Anti-neoplatic Chinese Herbal Medicine," The Commercial Press, Beijing, 1990, pp. $10-11,78-79$.

6) Zheng Y. T., Zhang W. F., Ben K. L., Wang J. H., Immunopharmacol. Immunotoxicol., 17, 69-79 (1995).

7) Ozaki Y., Xing L., Satake M., Biol. Pharm. Bull., 19, 1046-1048 (1996).

8) Xu W., Hou W., Yao G., Ji Y., Yeh M., Sun B., Biochem. Biophys. Res. Commun., 284, 168-172 (2001).
9) Lan P., Yan L., Xiao L., Chin. Med. J., 112, 1109-1111 (1999).

10) Oyama K., Fujimura T., Ninomiya I., Miyashita T., Kinami S., Fushida S., Ohta T., Koichi M., Carcinogenesis, 26, 565-570 (2005).

11) Tsuda H., Ohshima Y., Nomoto H., Fujita K., Matsuda E., Iigo M., Takasuka N., Moore M. A., Drug Metab. Pharmacokinet., 19, 245263 (2004)

12) Sun S. Y., Hail N., Jr., Lotran R., J. Natl. Cancer Inst., 96, 662-672 (2004)

13) Peng L., Jiang H., Bradley C., Hиа Xi Yi Ke Da Xие Xиe Bao, 32, $602-604$ (2001).

14) Mazzini G., Ferrari C., Erba E., Eur. J. Histochem., 47, 289-298 (2003).

15) Steller H., Science, 267, 1445-1449 (1995).

16) Stefanis L., Neuroscientist, 11, 50-62 (2005).

17) Fulda S., Scaffidi C., Pietsch T., Krammer P. H., Peter M. E., Debatin K. M., Cell Death Differ., 5, 884-893 (1998).

18) Johnson C. R., Jarvis W. D., Apoptosis, 9, 423 - 427 (2004).

19) Li H., Zhu H., Xu C. J., Yuan J., Cell, 94, 491—501 (1998).

20) Kluck R. M., Bossy-Wetzel E., Green D. R., Newmeyer D. D., Science, 275, 1132-1136 (1997). 